\title{
Implikasi Teori Belajar Bruner dalam Model Pembelajaran Kurikulum 2013
}

\author{
Sundari $^{\circledR}$ \& Endang Fauziati $^{2}$
}

Universitas Muhammadiyah Surakarta, Indonesia

$\bowtie$ E-mail: sundaridedy@gmail.com

\begin{abstract}
Abstrak
Penelitian ini bertujuan untuk menganalisa teori belajar kognitif Bruner dari kajian studi pustaka yang relevan dan mendeskripsikan implikasi teori belajar kognitif Bruner dalam model pembelajaran kurikulum 2013. Penelitian ini menggunakan metode library research, teknik pengumpulan data studi dokumen. Hasil dari penelitian studi pustaka menunjukkan bahwa: (1) Bruner menganggap manusia sebagai pemikir, pemroses, dan pencipta informasi; (2) tiga proses kognitif yang berlangsung dalam belajar yaitu: memperoleh informasi baru, transformasi pengetahuan, dan evaluasi; (3) supaya pengetahuan dapat dengan mudah ditransformasikan perlu memperhatikan empat tema pendidikan untuk perkembangan siswa yaitu; struktur pengetahuan, kesiapan, intuisi dan motivasi; (4) proses pembelajaran dapat terlaksana dengan baik melalui tiga tahapan perkembangan kognitif yaitu: enaktif, ikonik, dan simbolik tetapi urutan tahapan berpikir atau perkembangan kognitif tersebut tidak dikaitkan dengan usia siswa, Bruner lebih menekankan bagaimana siswa mengeksplorasi potensi yang dimiliki; (5) Bruner mengembangkan model belajar penemuan atau discovery learning. Model pembelajaran discovery learning yang dikembangkan Bruner dengan tiga tahapan perkembangan kognitif siswa (enaktif, ikonik, dan simbolik) merupakan salah satu model pembelajaran yang diterapkan dalam kurikulum 2013 di Indonesia.
\end{abstract}

Kata Kunci: Implikasi; Teori Buner; Model Pembelajaran; Kurikulum 2013

\begin{abstract}
This study aims to analyze Bruner's cognitive learning theory from relevant literature studies and describe the implications of Bruner's cognitive learning theory in the 2013 curriculum learning model. This study uses library research methods, document study data collection techniques. The results of the literature study show that: (1) Bruner considers humans as thinkers, processors, and creators of information; (2) three cognitive processes that take place in learning, namely: obtaining new information, transforming knowledge, and evaluating; (3) so that knowledge can be easily transformed, it is necessary to pay attention to four themes of education for student development, namely; knowledge structure, readiness, intuition and motivation; (4) the learning process can be carried out well through three stages of cognitive development, namely: enactive, iconic, and symbolic but the sequence of stages of thinking or cognitive development is not related to the age of students, Bruner emphasizes how students explore their potential; (5) Bruner developed a discovery learning model. The discovery learning model developed by Bruner with three stages of student cognitive development (enactive, iconic, and symbolic) is one of the learning models applied in the 2013 curriculum in Indonesia.
\end{abstract}

Keywords: Implications; Buner's Theory; Learning Model; 2013 Curriculum 


\section{PENDAHULUAN}

Pada era globalisasi seperti sekarang ini, ilmu pengetahuan dan teknologi berkembang dengan pesat, diiringi pula berkembangnya berbagai konsep dan wawasan baru tentang sistem pembelajaran di sekolah. Buto (2010) salah satu ciri dari pembelajaran dalam nuansa pendidikan modern, penyajiannya didasarkan pada teori belajar dari ahli atau pakar pendidikan.

Salah satu teori belajar yang digunakan dan dikembangkan dalam dunia pendidikan adalah teori belajar kognitif. Sutarto (2017) munculnya teori kognitif dilatarbelakangi adanya kritik terhadap teori behaviorisme yang dianggap terlalu sederhana, proses belajar hanya sebagai hubungan stimulusrespon. Bagi para penganut aliran teori kognitivisme, proses belajar melibatkan proses berfikir yang sangat kompleks melibatkan prinsip dasar psikologi, yaitu belajar aktif melalui pengalaman pribadi dan interaksi sosial.

Dalam belajar kognitif, proses belajar dianggap lebih penting ketimbang hasil belajar dan kegiatan belajar tidak dapat dipisahkan dari kehidupan manusia. Widyaningrum (2011) menurut Bruner, belajar adalah suatu proses aktif yang memungkinkan manusia menemukan sesuatu yang baru di luar informasi yang sudah diberikan kepadanya. Pengetahuan perlu dipelajari dengan tahap perkembangan kognitif supaya pengetahuan yang diperoleh dapat diinternalisasikan ke dalam pikiran atau struktur kognitif manusia yang mempelajarinya.

Teori belajar kognitif banyak dikembangkan para pakar atau ahli pendidikan untuk mendesain pendekatan, strategi, model, dan metode pembelajaran. Teori yang dikembangkan para ahli tersebut tentunya berpengaruh pada kurikulum yang diterapkan pada suatu negara. Kurikulum seharusnya memuat struktur pengetahuan yang berisi ide, gagasan, konsep dasar, dan hubungan antar konsep yang dianggap penting, dan pembelajaran pada suatu kurikulum akan berhasil jika diterapkan model pembelajaran yang sesuai dengan karakteristik dan perkembangan kognitif

Sebenarnya penelitian sebelumnya sudah banyak yang membahas tentang teori belajar kognitif dan implikasinya dalam pembelajaran secara umum beserta tokohtokohnya seperti: Jean Piaget Jean Piaget, Vygotsky, Bruner, Lewin, Ausebel, dan Gagne (Anidar, 2017; Ekawati, 2019; Nugroho, 2015; Nurhadi, 2020; Picauly, 2016; Sutarto, 2017).

Perbedaan dengan penelitian sebelumnya, penelitian ini fokus pada satu tokoh teori belajar kognitif yaitu Bruner dan implikasinya pada model pembelajaran kurikulum 2013. Berdasarkan latar belakang tersebut, penelitian ini bertujuan untuk menganalisa teori belajar kognitif menurut Bruner dari studi pustaka yang relevan dan mendeskripsikan implikasi teori belajar kognitif menurut Bruner dalam model pembelajaran kurikulum 2013.

\section{METODE PENELITIAN}

Jenis penelitian ini adalah penelitian kualitatif menggunakan metode studi kepustakaan. Sari \& Asmendri (2020) studi kepustakaan adalah kegiatan penelitian dengan cara mengumpulkan data dan informasi melalui material kepustakaan yaitu: buku referensi, catatan, artikel, jurnal, dan hasil penelitian sebelumnya yang relevan yang berkaitan dengan masalah yang akan dipecahkan.

Teknik pengumpulan data pada penelitian ini dengan teknik studi dokumen atau dokumentasi. Menurut Mirzaqon, T \& 
Purwoko (2017) teknik pengumpulan data penelitian kepustakaan dapat dilakukan dengan dokumentasi, yaitu suatu teknik pengumpulan data dengan cara mencari data dari buku, artikel, jurnal, catatan, makalah dan sebagainya yang relevan. Instrumen penelitian diantaranya: format, catatan penelitian daftar chelist klasifikasi dari bahan penelitian, dan skema penulisan.

Dalam penelitian ini sumber data primer berasal dari data yang terkait langsung dengan tema yang dibahas, sumber data berasal dari kajian jurnal yang sesuai dengan tema yang diteliti. Sari \& Asmendri (2020) sumber data primer langsung terkait dengan tema penelitian, data sekunder berupa data pendukung dari berbagai kajian jurnal yang sesuai dengan tema.

Data yang sudah dikumpulkan kemudian dianalisa menggunakan model Miles dan Huberman. Sugiyono (2017) menurut Milles dan Hubberman analisa data dilakukan secara terus menerus sampai tuntas dengan cara mengumpulkan data, reduksi data, penyajian data, dan kesimpulan.

\section{HASIL DAN PEMBAHASAN Teori Belajar Kognitif Bruner}

Bruner memiliki nama lengkap Jerome Seymour Bruner seorang ahli psikologi yang mempunyai kontribusi besar dalam teori belajar kognitif yang merupakan peralihan dari teori behaviorisme. Pada tanggal 1 Oktober 1915 Bruner lahir di New York Amerika. Pada tahun 1939 mendapat gelar MA dan 1941 mendapat gelar Ph.D di Harvard University (Arias Gallegos, 2016). A Study in Thinking adalah karya Bruner dalam mengawali kognitivisme (Nugroho, 2015). Bruner sebagai salah satu tokoh utama dalam revolusi kognitivisme dan eksistensinya bidang pendidikan berpengaruh besar pada proses pembelajaran (Anidar, 2017).

Bruner seorang tokoh ahli psikologi belajar kognitif dan tokoh perkembangan kognitif banyak melakukan penelitian tentang persepsi manusia, berfikir, belajar, dan motivasi. Menurut Bruner manusia sebagai pemikir, pemroses, dan pencipta informasi. Oleh karena itu, Bruner memusatkan perhatian pada sesuatu yang dilakukan manusia sesuai dengan informasi yang diterimanya untuk mencapai suatu pemahaman yang bermakna. (Arias Gallegos, 2016; Buto, 2010).

Pandangan Bruner tentang belajar sebagai proses perkembangan kognitif didasarkan pada dua asumsi yaitu: perolehan pengetahuan adalah proses interaktif seseorang dengan lingkungannya secara aktif akan terjadi perubahan terjadi pada diri seseorang dan lingkungannya, dan seseorang mengkonstruksikan pengetahuan yang dimiliki dengan menghubungkan informasi baru dan informasi yang diperoleh sebelumnya menjadi suatu struktur pengetahuan yang makna (Picauly, 2016).

Menurut Bruner, pada dasarnya belajar merupakan proses perkembangan kognitif yang terjadi dalam diri seseorang. Ada tiga proses kognitif yang berlangsung dalam belajar, yaitu: proses pemerolehan informasi baru, proses transformasi informasi, proses mengevaluasi atau menguji relevansi dan ketepatan pengetahuan (Anidar, 2017; Picauly, 2016; Sutarto, 2017). Pemerolehan informasi baru dilakukan melalui kegiatan membaca buku atau sumber lainnya yang sesuai, mendengarkan penjelasan guru, melihat audiovisual, dan sebagainya. Transformasi informasi yaitu tahap memahami, mencerna, dan menganalisis pengetahuan baru serta mentransformasikan dalam bentuk baru yang mungkin bermanfaat 
untuk hal-hal yang lain. Mengevaluasi atau menguji relevansi dan ketepatan dilakukan untuk mengetahui benar tidaknya hasil tranformasi, evaluasi kemudian dinilai sehingga nantinya dapat diketahui apakah pengetahuan yang diperoleh dapat dimanfaatkan dan ditransformasikan untuk memahami gejala-gejala lain.

Menurut Bruner, supaya pengetahuan mudah ditransformasikan oleh siswa, perlu memperhatikan empat tema pendidikan untuk perkembangan kognitif, yaitu: (1) struktur pengetahuan, dipandang penting bagi siswa untuk melihat keterhubungan fakta dengan informasi yang diterima; (2) kesiapan, untuk belajar diperlukan penguasaan keterampilan yang lebih tinggi lagi; (3) nilai intuisi, yaitu teknik intelektual untuk sampai pada formulasi tentatif tanpa menganalisis untuk mengetahui apakah formulasi tentatif merupakan kesimpulan yang benar; (4) dan motivasi, yaitu keadaan pada diri seseorang yang dapat mendorongnya melakukan sesuatu untuk mencapai tujuan (Buto, 2010; Sutarto, 2017). Dalam proses pembelajaran, struktur pengetahuan perlu memperhatikan karakteristik dan perkembangan kognitif siswa, kesiapan belajar dipengaruhi oleh pengalaman siswa dan kematangan psikologi. Cara belajar yang baik adalah melalui proses intuisi yaitu memahami hubungan, arti, dan konsep, kemudian menarik kesimpulan dengan cara diberikan motivasi sesuai dengan perkembangannya.

Menurut Bruner, proses belajar dapat terlaksana dengan baik jika pengetahuan dipelajari melalui tiga tahapan perkembangan kognitif siswa yaitu: enaktif (berbasis tindakan dan benda konkrit), ikonik (berbasis gambaran atau visualisasi), dan simbolik (berbasis simbol abstrak, bahasa, matematika, dan logika) (Buto, 2010;
Ekawati, 2019; Ervayani et al., 2016; Lestari, 2014; Nugroho, 2015; Nurhadi, 2020; Pahliwandari, 2016; Picauly, 2016; Sutarto, 2017; Widyaningrum, 2011).

Enaktif yaitu tahap perkembangan siswa memperoleh pengetahuan dengan melakukan pengamatan langsung terhadap fakta atau realita yang terjadi di lingkungan sekitar. Siswa dapat langsung mengamati benda konkrit pada situasi nyata, memegang, dan menggerakkannya.

Ikonik yaitu tahap perkembangan siswa memperoleh pengetahuan tidak secara langsung melalui benda konkrit atau situasi nyata pada lingkungan sekitar, melainkan melalui visualisasi verbal dan gambargambar. Siswa belajar melalui bentuk perumpamaan atau perbandingan.

Simbolik yaitu tahapan perkembangan siswa memperoleh pengetahuan melalui symbol bahasa, matematika, logika, dan sebagainya. Siswa mampu menyampaikan ide gagasan dalam bentuk abstrak yang dipengaruji tingkat perkembangannya.

Tiga tahapan perkembangan kognitif enaktif, ikonik, dan simbolik harus terintegrasi dan tidak dapat dijelaskan sebagai tahapan yang terpisah, bahkan sampai pembelajar dewasa akan lebih produktif saat memperoleh informasi baru dengan mengikuti tiga tahapan secara progresif mulai dari tahap enaktif ke ikonik kemudian simbolik.

Pada prinsipnya teori kognitif Bruner adalah pengembangan dari teori kognitif Jean Piaget dan Bruner lebih menekankan bagaimana individu mengeksplorasi potensi yang ada pada dirinya. Dari situlah terlahir teori belajar penemuan atau discovery learning dimana siswa secara aktif mencari pemecahan masalah melalui tiga tahapan perkembangan kognitif yang terintegrasi, kemudian menghasilkan pengetahuan baru 
yang benar-benar bermakna. Hal tersebut sejalan dengan. Buto (2010) menurut Bruner, teori belajar penemuan (discovery learning) adalah proses dimana siswa dapat memahami makna, konsep, dan hubungan melalui proses intuisi, sampai pada akhirnya dapat menemukan suatu kesimpulan yang disesuikan dengan perkembangan kognitif siswa. Ekawati (2019) Bruner menyarankan hendaknya siswa diberikan kesempatan yang luas untuk menjadi seorang scientist, problem solver, historia atau ahli matematika, menemukan konsep dan arti kemudian menjabarkannya dalam bahasa yang siswa pahami.

Bruner menjelaskan peran guru dalam belajar penemuan diantaranya: (1) guru sebagai fasilitator dan tidak begitu mengendalikan proses pembelajaran; (2) guru harus pandai menstimulasi atau memunculkan masalah, siswa memecahkan sendiri solusinya; (3) dan membimbing dan memotivasi siswa untuk menemukan konsep, menemukan hubungan antar bagian struktur materi dan membuat kesimpulan.

Kesimpulan dari hasil studi pustaka yang relevan, seperti pada penjabaran di atas dapat disimpulkan bahwa Bruner merupakan tokoh ahli psikologi perkembangan dan ahli psikologi belajar kognitif. Bruner menganggap manusia sebagai pemikir, pemroses, dan pencipta informasi. Menurut Bruner, pada dasarnya belajar merupakan proses perkembangan kognitif yang terjadi dalam diri seseorang dan ada tiga proses kognitif yang berlangsung dalam belajar yaitu: memperoleh informasi baru, transformasi pengetahuan, dan evaluasi. Supaya pengetahuan dapat dengan mudah ditransformasikan perlu memperhatikan yaitu; struktur pengetahuan, kesiapan, intuisi dan motivasi.

Menurut Bruner, proses belajar dapat terlaksana dengan baik jika melalui tiga tahapan perkembangan kognitif yaitu: enaktif, ikonik, dan simbolik tetapi urutan tahapan perkembangan kognitif tersebut tidak dikaitkan dengan usia siswa. Bruner lebih menekankan bagaimana siswa mengeksplorasi potensi yang dimiliki sesuai tingkat perkembangan kognitif dan proses belajar lebih diutamakan daripada hasil belajar, oleh karena itu Bruner mengembangkan model belajar penemuan atau discovery learning.

\section{Implikasi Teori Belajar Kognitif Bruner dalam Model Pembelajaran Kurikulum 2013}

Menurut Bruner ada tiga proses kognitif yang berlangsung dalam proses belajar, yaitu: pemerolehan informasi, transformasi informasi, dan mengevaluasi (menguji relevansi dan ketepatan). Hal tersebut sesuai dengan Ariyana, dkk (2019) menurut Permendikbud Nomor 12 tahun 2016 tentang Standar Proses, proses pembelajaran kurikulum 2013 dipadankan dengan proses ilmiah dengan metode ilmiah yang merujuk pada teknik-teknik investigasi fenomena atau gejala, mendapat pengetahuan baru, mengoreksi, dan memadukan pengetahuan sebelumnya.

Menurut Bruner pembelajaran adalah kegiatan dimana siswa belajar terlibat aktif dengan prinsip-prinsip dan konsep-konsep dalam pemecahan masalah dan guru bertindak sebagai motivator, yaitu memotivasi siswa memperoleh pengalaman yang memungkinkan siswa menemukan dan memecahkan masalah sesuai dengan tingkat perkembangannya.

Bruner lebih peduli terhadap proses pembelajaran dari pada hasil belajar. menurut Bruner metode atau model belajar adalah salah satu faktor penentu keberhasilan dalam proses pembelajaran dibandingkan hanya 
dengan pemerolehan pengetahuan khusus dari guru. Model pembelajaran yang dimaksud adalah model belajar penemuan atau sering disebut dengan discovery learning. Sutarto (2017) discovery learning atau belajar penemuan adalah model pembelajaran yang dikembangkan Bruner berdasarkan pada pandangan perkembangan kognitif tentang pembelajaran dan prinsip konstruktivisme.

Discovery learning mempunyai prinsip yang sama dengan inquiry. Kemdikbud (2014) tidak ada perbedaan yang prinsip antara discovery learning dengan inquiry, yang membedakan, untuk discovery masalah yang dihadapkan kepada siswa merupakan semacam masalah yang direkayasa guru, sedangkan pada inquiry masalahnya bukan hasil rekayasa, siswa harus mengerahkan pikiran dan ketrampilannya untuk menemukan sesuatu yang baru dari masalah melalui penelitian.

Tahapan model pembelajaran discovery learning menurut Bruner antara lain: stimulation (pemberian rangsangan atau stimulus), problem statement (identifikasi masalah atau pernyataan), data collection (pengumpulan data), data processing (pengolahan data), verification (pembuktian), dan generalization (menarik kesimpulan atau generalisasi) (Ariyana et al., 2019).

Stimulation (pemberian rangsangan) yaitu siswa diberikan pertanyaan oleh guru dengan tujuan merangsang siswa untuk berfikir kritis. Problem Statement (mengidentifikasi masalah) yaitu siswa diberikan kesempatan mengidentifikasi masalah yang relevan dengan bahan pembelajaran kemudian memilih dan merumuskan dalam bentuk hipotesa atau jawaban sementara. Data collection (pengumpulan data) yaitu siswa diberikan kesempatan untuk mengumpulkan informasi sebanyak-banyaknya yang relevan dengan masalah untuk membuktikan benar tidaknya hipotesa yang sudah dibuat. Data Processing (pengolahan data) yaitu siswa mengolah data yang sudah diperoleh kemudian data tersebut ditafsirkan dengan bimbingan guru. Verification (pembuktian) yaitu siswa diberikan kesempatan membuktikan benar tidaknya hipotesis awal dengan pemeriksaan secara cermat, menemukan konsep, dan dihubungkan dengan hasil pengolahan data. Generalization (generalisasi) yaitu siswa menarik kesimpulan untuk dijadikan prinsip umum yang berlaku untuk semua masalah yang sama atau kejadian dengan memperhatikan hasil verifikasi

Proses pembelajaran akan berhasil dengan baik dan kreatif jika didukung manipulasi bahan pembelajaran yang sesuai dengan tingkat perkembangan kognitif siswa, sehingga dapat memfasilitasi kemampuan siswa untuk berfikir atau mempresentasikan apa yang mereka pahami sesuai dengan tingkat perkembangannya. Buto (2010) menurut Bruner perkembangan kognitif siswa terjadi melalui tiga tahapan yang ditentukan dengan caranya memahami lingkungan yaitu tahap enaktif, ikonik, dan simbolik.

Teori belajar penemuan atau discovery learning dengan tiga tahap perkembangan kognitif (enaktif, ikonik, dan simbolik) yang dikembangkan oleh Bruner dapat memberikan masukan yang sangat besar bagi perkembangan pendidikan di Indonesia terutama pada model pembelajaran yang diterapkan pada kurikulum 2013 di Indonesia. Ariyana et al., (2019) menurut Permendikbud Nomor 12 tahun 2016 tentang Standar Proses, implementasi kurikulum 2013 di Indonesia menggunakan tiga model pembelajaran dengan metode ilmiah yaitu: model pembelajaran berbasis masalah 
(Problem Based Learning), model pembelajaran penemuan (Inquiry atau Discovery Learning), dan model pembelajaran berbasis proyek (Project Based Learning ).

Peran guru dalam mengaplikasikan model belajar penemuan atau discovery learning diantaranya: (1) guru sebagai fasilitator dan tidak begitu mengendalikan proses pembelajaran, (2) guru harus pandai menstimulasi atau memunculkan masalah untuk dipecahkan siswa (3) membimbing dan memotivasi siswa untuk menemukan konsep, menemukan hubungan antar bagian struktur materi dan membuat kesimpulan.

Kelebihan belajar penemuan atau discovery learning menurut Bruner antara lain: kemampuan intelektual ada nilai tambah, kemampuan intrinsik lebih ditekankan daripada ekstrinsik, anak belajar menemukan pengetahuannya sendiri, dan memungkinkan lebih lama mengingat informasi yang diperoleh (Buto, 2010; Ekawati, 2019). Menurut Bruner pengetahuan yang didapatkan dari belajar penemuan mempunyai efek transfer yang lebih baik dan akan bertahan lama pada diri siswa. Dengan belajar penemuan akan meningkatkan kemampuan berfikir kritis, bernalar, dan melatih ketrampilan kognitif untuk menemukan pemecahan masalah. Pembelajaran akan lebih bermakna bagi siswa jika mereka memusatkan perhatiannya dan berperan aktif dengan mengidentifikasi sendiri konsep kunci dalam memahami struktur pengetahuan yang dipelajari.

Penemuan yang dimaksud dalam discovery learning bukan penemuan yang murni, karena konsep, arti, dan hubungan yang ditemukan siswa sebenarnya sudah ditemukan oranglain. Penemuan yang dimaksud penemuan konsep bagi siswa yang mungkin hanya sebagian saja karena dalam belajar tetap dibimbing oleh guru.

Bruner menyadari bahwa penerapan belajar penemuan yang murni memerlukan waktu yang cukup lama. Karena itu, dalam bukunya the relevance of education (1971) Bruner menyarankan agar metode belajar penemuan hanya diterapkan sampai batas tertentu, dengan mengarahkan pada struktur bidang studi (Buto, 2010). Guru harus pandai melakukan identifikasi muatan pelajaran atau bidang studi yang bisa diterapkan dengan model pembelajaran discovery learning dengan tiga tahap perkembangan kognitif.

Kesimpulan dari pembahasan tentang implikasi teori belajar kognitif Bruner di atas dapat disimpulkan bahwa model belajar penemuan atau discovery learning yang dikembangkan Bruner dengan tiga tahapan perkembangan kognitif siswa (enaktif, ikonik, dan simbolik) merupakan salah satu model pembelajaran yang dapat diterapkan dalam kurikulum 2013.

\section{KESIMPULAN}

Hasil dari penelitian studi pustaka dapat disimpulkan bahwa: (1) Bruner menganggap manusia sebagai pemikir, pemroses, dan pencipta informasi; (2) tiga proses kognitif yang berlangsung dalam belajar yaitu: memperoleh informasi baru, transformasi pengetahuan, dan evaluasi; (3) supaya pengetahuan dapat dengan mudah ditransformasikan perlu memperhatikan empat tema pendidikan untuk perkembangan siswa yaitu; struktur pengetahuan, kesiapan, intuisi dan motivasi; (4) proses pembelajaran dapat terlaksana dengan baik melalui tiga tahapan perkembangan kognitif yaitu: enaktif, ikonik, dan simbolik tetapi urutan tahapan berpikir atau perkembangan kognitif tersebut tidak dikaitkan dengan usia siswa, Bruner lebih menekankan bagaimana siswa mengeksplorasi potensi yang dimiliki; (5) 
Bruner mengembangkan model belajar penemuan atau discovery learning.

Model belajar penemuan atau discovery learning yang dikembangkan Bruner dengan tiga tahapan perkembangan kognitif siswa (enaktif, ikonik, dan simbolik) merupakan salah satu model pembelajaran ilmiah yang diterapkan dalam kurikulum 2013 di Indonesia.

\section{DAFTAR RUJUKAN}

Anidar, J. (2017). Teori Belajar Menurut Aliran Kognitif serta Implikasinya Dalam Pembelajaran. Jurnal Al-Taujih: Bingkai Bimbingan Dan Konseling Islami, 3(2), 8-16.

Arias Gallegos, W. L. (2016). In Memoriam Jerome Bruner (1915-2016). Propósitos y Representaciones, 4(2), 2-5.

https://doi.org/10.20511/pyr2016.v4n2. 127

Ariyana, Y., Pudjiastuti, A., Bestary, R., \& Zamrony. (2019). Buku Pegangan Pembelajaran Berorientasi Pada Keterampilan Berpikir Tingkat Tinggi. Direktorat Jendral Guru dan Tenaga Kependidikan Kemdikbud.

Buto, Z. A. (2010). Implikasi Teori Pembelajaran Jerome Bruner Dalam Nuansa Pendidikan Modern. Millah, $e d$ (khus), 55-69. https://doi.org/10.20885/millah.ed.khus .art3

Ekawati, M. (2019). Teori Belajar Menurut Aliran Psikologi Kognitif Serta Implikasinya Dalam Proses Belajar dan Pembelajaran. Seminar Nasional: Jambore Konseling 3, 7 (4)

Ervayani, Holisin, I., \& Shoffa, S. (2016). Penerapan Teori Belajar Bruner dengan Pendekatan Pendidikan Matematika Realistik di Kelas III SD
Muhammadiyah 9 Surabaya. MUST: Journal of Mathematics Education, Science and Technology, 1(1), 113124.

https://doi.org/10.30651/must.v1i1.102

Kemdikbud. (2014). Materi Pelatihan Guru Implementasi Kurikulum 2013. Badan Pengembangan Sumber Daya Manusia Pendidikan dan Kebudayaan dan Penjaminan Mutu Pendidikan.

Lestari, D. (2014). Penerapan Teori Bruner Untuk Meningkatkan Hasil Belajar Siswa Pada Pembelajaran Simetri Lipat di Kelas IV SDN 02 Makmur Jaya Kabupaten Maтuju Utara. 3(2), 129-141.

http://library1.nida.ac.th/termpaper6/sd /2554/19755.pdf

Mirzaqon, T, A., \& Purwoko, B. (2017). Studi Kepustakaan Mengenai Landasan Teori dan Praktik Konseling Expressive Writing. Jurnal BK Unesa, $8(1)$.

Nugroho, P. (2015). Pandangan Kognitifisme dan Aplikasinya Dalam Pembelajaran Pendidikan Agama Islam Anak Usia Dini. Antimicrobial Agents and Chemotherapy, 3(2), 45-52. https://doi.org/10.1017/CBO97811074 15324.004

Nurhadi. (2020). Teori Kognitivisme Serta Aplikasinya Dalam Pembelajaran. EDISI: Jurnal Edukasi Dan Sains, 2(1), 13-10. https://ejournal.stitpn.ac.id/index.php/e disi

Pahliwandari, R. (2016). Penerapan Teori Pembelajaran Kognitif dalam Pembelajaran Pendidikan Jasmani dan Kesehatan. Jurnal Pendidikan, 5(2), 154-164.

Picauly, V. E. (2016). Pandangan Jean Piaget dan Jerome Bruner tentang Pendidikan. 
Jurnal Pendidikan "Jendela Pengetahuan,” 9(April), 35-47.

Sari, M., \& Asmendri. (2020). Penelitian Kepustakaan (Library Research) dalam Penelitian Pendidikan IPA. Penelitian Kepustakaan (Library Research) Dalam Penelitian Pendidikan IPA, 6(1), 41-53. https://ejournal.uinib.ac.id/jurnal/index. php/naturalscience/article/view/1555/1 159

Sugiyono. (2017). Metode Penelitian
Kuantitatif, Kualitatif dan $R$ \& D. Alfabeta.

Sutarto. (2017). Teori Kognatif 5. Islamic Counselling, 1(02), 1-26.

Widyaningrum, R. (2011). Tahapan J. Bruner Dalam Pembelajaran Matematika Pada Penjumlahan Dan Pengurangan Bilangan Bulat Di Sekolah Dasar (Sd/Mi). Jurnal Cendekia, 9, 68-69. http://jurnal.iainponorogo.ac.id/index.p hp/cendekia/article/view/865 